\title{
El viajero estadounidense Ephraim George Squier y la prospección florística de Honduras (1849-1856)*
}

\section{Resumen}

Honduras recibió varios viajeros a partir de su independencia con el propósito de aquilatar sus recursos naturales para incorporarlos al comercio mundial. Uno de estos fue el estadounidense Ephraim George Squier, quien en 1870 publicó Honduras: Descriptive Historical and Statistical, un libro resultado de sus diferentes viajes. El artículo analiza cómo el libro presentó al público estadounidense tanto la descripción de los periplos del viajero como las oportunidades comerciales que presentaba Honduras bajo la sanción de la ciencia. Se concluye que Squier llevó a cabo una amplia prospección de la flora como parte de los propósitos geopolíticos estadounidenses por apropiarse de los recursos naturales hondureños con la exclusión de la élite local. La botánica fue la disciplina científica con la cual Squier hizo el inventario florístico en el marco del expansionismo estadounidense decimonónico. Squier es un ejemplo de la participación de los viajeros estadounidenses en la exploración naturalista de Centroamérica.

\section{Palabras clave}

Tesauro: vegetación, comercio internacional.

Autor: viajantes, historia natural de Honduras.

Referencia bibliográfica para citar este artículo: Vega, Rodrigo Antonio y Báez, Ortega. "El viajero estadounidense Ephraim George Squier y la prospección florística de Honduras (1849-1856)". Anuario de Historia Regional y de las Fronteras 26.2 (2021): 111-135.

Fecha de recepción: 16/10/2020

Fecha de aceptación: 14/02/2021

Rodrigo Antonio Vega y Ortega Báez: Doctor en Historia. Profesor de Carrera de la Facultad de Filosofía y Letras de la Universidad Nacional Autónoma de México. Correo electrónico: rodrigo.vegayortega@ gmail.com. Código ORCID: 0000-0002-3333-3536.

\footnotetext{
* Artículo de investigación resultado del Proyecto PAPIIT IN 302519 "Científicos, empresarios y funcionarios en la construcción del conocimiento y su aplicación práctica en México (1815-1940)", Instituto de Geografía de la Universidad Nacional Autónoma de México.
} 


\title{
The American Traveler Ephraim George Squier and the Floristic Prospecting of Honduras, 1849-1856
}

\begin{abstract}
Honduras received several travelers since its independence with the objective of assessing its natural resources to incorporate them into world trade. One of these was the American Ephraim George Squier, who in 1870 published Honduras: Descriptive Historical and Statistical, a book resulting from his different travels. The article analyzes how the book presented to the American public both the description of the travels of the traveler and the commercial opportunities that Honduras presented under the sanction of science. It is concluded that Squier carried out an extensive survey of the flora as part of the United States'geopolitical intentions to appropriate the Honduran natural resources to the exclusion of the local elite. Botany was the scientific discipline with which Squier made the floristic inventory within the framework of nineteenth-century American expansionism. Squier is an example of the involvement of American travelers in the naturalistic exploration of Central America.
\end{abstract}

\section{Keywords}

Tesauro: Vegetation, International Trade.

Author: Travelers, natural history of Honduras.

\section{$O$ viajante americano Ephraim George Squier e a prospecção florística de Honduras, 1849-1856}

\section{Resumo}

Honduras recebeu vários viajantes desde sua independência com o objetivo de avaliar seus recursos naturais para incorporá-los ao comércio mundial. Um deles foi o americano Ephraim George Squier, que em 1870 publicou Honduras: Descriptive Historical and Statistical, livro resultante de suas diferentes viagens. $O$ artigo analisa como o livro apresentou ao público americano tanto a descrição das viagens do viajante quanto as oportunidades comerciais que Honduras apresentou sob a sanção da ciência. Conclui-se que Squier realizou um extenso levantamento da flora como parte das intenções geopolíticas dos Estados Unidos de se apropriar dos recursos naturais hondurenhos com exclusão da elite local. Botânica foi a disciplina científica com a qual Squier fez o inventário florístico dentro da estrutura do expansionismo americano do século XIX. Squier é um exemplo do envolvimento de viajantes americanos na exploração naturalista da América Central.

\section{Palavras-chave}

Tesauro: Vegetação, Comércio internacional.

Autor: Viajantes, História natural de Honduras. 


\section{Introducción}

Ephraim George Squier (1821-1888) fue uno de los viajeros estadounidenses más destacados en cuanto a la publicación de literatura de viaje sobre Centroamérica entre 1852 y 1880. En particular, Squier en 1870 publicó Honduras: Descriptive Historical and Statistical, resultado de sus diferentes viajes a este país centroamericano. En español se tradujo el mismo año por Carlos Gutiérrez, bajo el título de Honduras descriptiva, histórica y estadística; y en 1908 tuvo lugar una edición corregida y anotada por José María Cuéllar, con el título de Honduras. Descripción Histórica, Geográfica y Estadística de esta República de la América Central. ${ }^{1}$ La segunda edición es la más completa y apegada a la obra original, razón por la cual es la base de esta investigación.

La participación diplomática, política y periodística de Squier ha sido abordada por Mariana Mould de Pease, Terry A. Barnhart, Rafael Heliodoro Valle, Francisco Aguirre, Jaime Incer, Jimmy Avilés, Ligia Madrigal y Liliana Weinberg. ${ }^{2}$ No obstante, hasta el momento, la obra de Squier ha pasado inadvertida en la historia de la ciencia latinoamericana a pesar de su impronta científica, y ha recibido mayor interés en sus aspectos económicos y geopolíticos. Por esta razón, analizamos Honduras. Descripción Histórica, Geográfica y Estadística de esta República de la América Central a la luz de los intereses prospectivos sobre la flora nativa por su autor y su práctica amateur de la ciencia.

Squier es un ejemplo de la práctica amateur de la ciencia decimonónica, en la cual destacaron individuos que carecían de un título profesional, pero desempeñaron actividades especializadas, en este caso en la botánica, pero también en relación con la meteorología, la geografía, la astronomía, la geología, entre otras disciplinas. Varios de los viajeros que recorrieron América Latina se encuentran dentro de esta categoría. ${ }^{3}$

La hipótesis es que el libro de viaje de Squier presenta un estudio científico de carácter prospectivo de la flora hondureña por su utilidad para la expansión económica estadounidense. El relato de viaje de Squier deja ver cómo su país estaba dispuesto a apropiarse de los recursos naturales de Honduras para acoplarlos en la estrategia geopolítica para alcanzar dicha expansión. Por prospección entendemos la exploración de

\footnotetext{
${ }^{1}$ El libro se divide de la siguiente manera: Prólogo del traductor; Introducción; Capítulo I. Posición geográfica y topográfica de Centro América, y su influencia acerca de la población; Capítulo II. Descubrimiento, Límites, Aspecto general y Topografía; Capítulo III. Ríos, lagos y lagunas; Capítulo IV. Bahías, puertos y fondeaderos; Capítulo V. Islas de Honduras; Capítulo VIII. Divisiones Políticas. Departamentos de Comayagua, Gracias, Choluteca, Tegucigalpa, Olancho, Yoro y Santa Bárbara; Capítulo IX. Aspecto natural de Honduras; Capítulo X. Minas y minerales; Capítulo XI. Maderas preciosas, Producciones vegetales, Animales, Peces, Reptiles e Insectos; Capítulo XII. Existencia de los aborígenes; Capítulo XIII. Organización política; Capítulo XIV. Camino de hierro interoceánico; y Apéndice. Por un error de edición, la estructura del libro salta del capítulo V al VIII, omitiendo los numerales VI y VII. También se eligió esta edición por su facilidad de consulta al estar resguardada en la Biblioteca Nacional de México.

${ }^{2}$ Estos autores son citados a lo largo del artículo.

${ }^{3}$ Véase Agustí Nieto-Galan, Los públicos de la ciencia. Expertos y profanos a través de la historia (Madrid: Marcial Pons Historia, 2011).
} 
los recursos naturales (flora, fauna y mineralia) a partir del examen de las características del territorio y la naturaleza de un país o región. ${ }^{4}$ Los resultados científicos de Squier estuvieron enmarcados en el colonialismo sin colonias, estrategia geopolítica propia del proceso de globalización de mediados de la centuria, como se verá más adelante.

El objetivo del artículo es examinar la prospección que Squier realizó sobre la flora hondureña reflejada en su libro de viaje como parte de los propósitos estadounidenses por apropiarse de los recursos naturales de este país. La metodología se basa en la concepción del viajero como un actor destacado en la expansión global de la ciencia a partir "del dominio y control de las materias primas" de los países tropicales rumbo a los centros industriales europeos y estadounidenses como se refleja en la literatura de viaje. ${ }^{5}$ La metodología también reconoce que la ciencia decimonónica formó parte de los saberes, conocimientos y prácticas que las metrópolis occidentales emplearon en la dominación colonial de las jóvenes naciones latinoamericanas con el propósito de incorporar sus recursos naturales en la dinámica industrial. ${ }^{6}$ De acuerdo con Stefanía Gallini, la tríada territorios-mercancías-saberes permeó la literatura científica en inglés, francés y alemán, incluyendo los diarios de viaje, centrada en las formas que cobró la prospección "territorial y de recursos, las implicaciones ambientales de los bienes producidos y exportados desde América Latina y el papel de los nuevos conocimientos capaces de estimular la expansión territorial" de las metrópolis industriales. ${ }^{7}$

El artículo se divide en: i) introducción; ii) semblanza de Squier; iii) contexto de Honduras, iv) análisis del prólogo, v) la prospección de la flora en los departamentos y vi) el estudio de las producciones vegetales indígenas y aclimatadas.

La mayoría de los viajeros que recorrieron América Latina a partir de la década de 1820 se desempeñaron como ingenieros, abogados, médicos, diplomáticos, comerciantes, soldados, empresarios, marineros, artistas y sacerdotes, quienes en sus libros plasmaron aspectos de política, economía, relaciones diplomáticas, geografía, recursos naturales, costumbres, religión, desarrollo cultural, diversidad de grupos sociales, clima, entre otros temas, del país que recorrían ${ }^{8}$. Desde la misma década, en Europa y América se publicaron numerosos relatos de viajeros que saciaron "la creciente demanda de un público ávido de este tipo de literatura" que retrataba a

\footnotetext{
${ }^{4}$ Christian Brannstrom y Stefania Gallini, "An Introduction to Latin American Environmental History", en Brannstrom, Christian (ed.), Territories, Commodities and Knowledges. Latin American Environmental Histories in the Nineteenth and Twentieth Centuries (London: Institute for the Study of the Americas, 2004) 6.

${ }^{5}$ Mary Louise Pratt, Imperial Eyes. Travel Writing and Transculturation (New York: Routledge Taylor and Francis Group, 2003) 4.

${ }^{6}$ Luz Fernanda Azuela, "Imperialismo y ciencia. La Royal Geographical Society en el Perú (1880-1900)", en Patricia Escandón y Azuela, Luz Fernanda (coords.), Historia del quehacer científico en América Latina (México: Universidad Nacional Autónoma de México, 1993) 77.

${ }^{7}$ Stefanía Gallini, "Historia, ambiente, política: el camino de la historia ambiental en América Latina", Nómadas 30, Universidad Central, (2009): 97.

${ }^{8}$ Walther L Bernecker,"Literatura de viajes como fuente histórica para el México decimonónico: Humboldt, inversiones e intervenciones", Tzintzun, 38 (2003): 43.
} 
las naciones recién independizadas. ${ }^{9}$ Además, la literatura de viaje plasmó dos tipos de observaciones por parte del autor: primero, la realizada "en el momento, muchas veces sin mayores consideraciones y sin apasionamiento de ningún tipo"; y segundo, la expuesta a partir de una amplia reflexión posterior al concluir el periplo y en ocasiones contrastando la experiencia personal con otros viajeros. ${ }^{10}$ La literatura de viaje convocó a un numeroso público en Europa y América por las características de una narrativa basada en los hechos descritos por el autor, es decir, "en la realidad, en los testimonios" a partir de las experiencias personales, así como de comentarios sobre su apreciación de las problemáticas de los países recorridos y todo ello verificable por cualquier otro viajero o migrante. ${ }^{11}$

Las narraciones de viaje contribuyeron al reconocimiento científico de los jóvenes países de América, en especial en lo relativo a la descripción del territorio y la prospección de los recursos naturales, tanto los de tradición colonial como los escasamente aprovechados. ${ }^{12}$ En este sentido, varios científicos retomaron los pasos de Alexander von Humbodt al emprender viajes con el propósito de acopiar información meteorológica, geográfica, natural, geológica y social aún desconocida en las metrópolis científicas del siglo XIX, por ejemplo, Londres, París, Berlín o Nueva York. ${ }^{13}$

En particular, la naturaleza latinoamericana fue valorada por los viajeros como plena de "fertilidad y belleza, de manera que la capacidad productiva de las tierras les confería su calidad de hermosas". ${ }^{14}$ Además, para varios viajeros las especies vegetales, animales y minerales de los países de América Latina eran susceptibles de "proporcionar un importante caudal de ingresos que favorecería los progresos económicos" del país de origen del autor, como Estados Unidos para Squier. ${ }^{15}$ Vale la pena tomar en cuenta que los viajeros no solo regresaban a sus países de origen con la información acopiada durante el periplo, "sino que regresaban también cargados de colecciones de especies vegetales y animales desconocidas, de rocas y piezas arqueológicas" que se depositaban en colecciones públicas y privadas de las metrópolis científicas. ${ }^{16}$

\footnotetext{
${ }^{9}$ Francisco Uzcanga, "El relato de viaje en la prensa de la Ilustración: entre el prodesse et delectare y la instrumentalización satírica”, Revista de Literatura, LXXIII, 145 (2011): 222.

${ }^{10}$ Juan Rodríguez Gómez, "La literatura de viajes como fuente histórica: aproximación a las observaciones políticas de los viajeros colombianos en Venezuela", Historia Crítica, 16 (1999): 62.

${ }^{11}$ Leonardo Romero, "Imágenes poéticas en textos de viajes románticos al sur de España”, Revista de Literatura, LXXIII, 145 (2011): 239.

${ }_{12}$ María Rubio, "En los límites del libro de viajes: seducción, canonicidad y transgresión de un género", Revista de Literatura, LXXIII, 145 (2011): 66.

${ }_{13}$ Chozas, Diego. La literatura de viaje en El Museo Universal (1857-1869), (tesis de doctorado, Universidad de Zaragoza, 2014) 64.

${ }^{14}$ Luis Albuquerque, "Los libros de viaje como género literario", en Lucena, Manuel y Pimentel, Juan (eds.), Estudios sobre literatura de viajes (Madrid: Consejo Superior de Investigaciones Científicas, 2006) 86.

15 Esther Ortas, Viajeros ante el paisaje aragonés (1759-1850) (Zaragoza: Consejo Superior de Investigaciones Científicas, 1999) 59.

${ }^{16}$ Jean-Joinville Vacher y Clara López Beltrán, “Prólogo”, Bulletin de L'Institut Français d'Études Andines,
} 
Algunos viajeros al recorrer América Latina en el siglo XIX plasmaron en sus libros las capacidades productivas de los recursos naturales del país que conocían en su periplo, ya fuera como una prospección empírica o sistemática. Al respecto, Ephraim George Squier, como otros miembros del cuerpo diplomático de las potencias decimonónicas, fungió como actor de la ciencia al recabar información de los recursos naturales hondureños "que permitiera a los inversionistas hacer cálculos y proyectos de inversión" en el marco de la expansión económica de Estados Unidos. ${ }^{17}$ Por ello no es extraño que Squier se haya dado a la tarea de escribir varios libros y folletos de viaje a partir de su experiencia consular.

A la par de la prospección, en Honduras se estableció una dinámica de colonialismo sin colonias. De acuerdo con Jürgen Osterhammel y Jan Jansen, el colonialismo es el proceso de conquista y apropiación de tierras y recursos por parte de una sociedad sobre otra en la que se establece una relación de dominio. ${ }^{18}$ En este tipo de relación se ejerce la "explotación económica (mediante monopolios comerciales, aprovechamiento de recursos minerales, recaudación de tributos), aseguramiento estratégico de la política imperial, y obtención de mayor prestigio" ${ }^{19}$ El colonialismo que buscaban ejercer Estados Unidos y Gran Bretaña en Centroamérica era de tipo colonialismo sin colonias, es decir, basado en la "voluntad de poner a las sociedades periféricas al servicio de las metrópolis" sin una ocupación formal. ${ }^{20}$ Esto enfrentaría gradualmente a ambas potencias entre 1821 y 1850 , hasta la firma del tratado ClaytonBulwer (1850), que se mencionará más adelante.

El colonialismo sin colonias estuvo enmarcado en el proceso de globalización, es decir, en el conjunto "de procesos crecientes de interconexión y de interdependencia entre las distintas partes del planeta, en los que fluyen personas, ideas y objetos", incluyendo los del ámbito de la ciencia y, en particular, cómo ésta promovió la conexión entre países mediante la prospección naturalista que en el siglo XIX emprendieron varios viajeros. ${ }^{21}$ En este contexto, Centroamérica ocupó un lugar destacado por su carácter geoestratégico como "puente entre dos masas continentales y de istmo entre dos océanos", así como por lo endeble de su soberanía durante la primera mitad de la centuria. ${ }^{22}$

A partir de la política colonial sin colonias de Estados Unidos, los recursos naturales latinoamericanos paulatinamente se convirtieron en materias primas orientadas

\footnotetext{
XXXII, 3 (2003): 414.

${ }^{17}$ Alma Parra, "Cónsules y empresarios, expresión local del expansionismo estadounidense hacia finales del siglo XIX”, Secuencia, 48 (2000): 176.

${ }^{18}$ Jürgen Osterhammel y Jan Jansen, Colonialismo. Historia, formas, efectos (Madrid: Siglo XXI, 2019): 11.

${ }^{19}$ Osterhammel y Jansen 20.

${ }^{20}$ Osterhammel y Jansen 26.

${ }^{21}$ Víctor Hugo Acuña, "Centroamérica en las globalizaciones (siglos XVI-XXI)”, Anuario de Estudios Centroamericanos, XLI (2015): 14.

${ }^{22}$ Rafal Reichert, "El golfo de Honduras: estrategias geopolíticas y militares de una frontera imperial, siglos XVI-XVIII”, Tzintzun, 65 (2017): 15.
} 
a su economía al controlar los "productos vegetales; movilizando la mano de obra no blanca y aprendiendo a dominar las enfermedades tropicales". ${ }^{23}$ En el siglo XIX, la botánica fue una de las principales disciplinas para la apropiación colonial de las regiones tropicales que iniciaba con la prospección de los viajeros europeos y estadounidenses, y continuaba con la llegada de empresarios dispuestos a invertir en la explotación de los recursos naturales, por ejemplo, en la silvicultura y la agroexportación. ${ }^{24}$

A la par de la estrategia geopolítica estadounidense del colonialismo sin colonias, a mediados de la centuria se establecieron "centros" industriales y "periferias" suministradoras de recursos naturales bajo el modelo de economías agroexportadoras en el marco del auge del capitalismo. ${ }^{25}$ En esta dinámica global, desde los centros industriales partieron viajeros especializados en ciencia con el propósito de reconocer las materias primas tropicales y las especies vegetales susceptibles de aclimatación para surtir el mercado global de consumo, como el caso de Honduras y el resto de países centroamericanos. La literatura de viaje refleja la prospección naturalista al poner en contacto a los científicos, políticos y empresarios de Estados Unidos interesados en los recursos naturales de Centroamérica. Además, "el comercio y los viajes científicos abrieron una puerta al tráfico de especies vegetales para los naturalistas" estadounidenses. ${ }^{26}$ Vale la pena señalar que los viajeros científicos en general se retrataban en sus libros como "actores fundamentales en el éxito económico de la nación y creían en que sus conocimientos científicos eran esenciales" para afianzar el colonialismo estadounidense a partir del acopio de datos prospectivos. ${ }^{27}$

\section{Semblanza de Ephraim George Squier}

Ephraim George Squier nació el 17 de junio de 1821 en Bethlehem (Nueva York). Fue hijo del ministro metodista Joel Squier y Katherine Kilmer. E. G. Squier inició una carrera inconclusa como maestro de primeras letras y después cursó algunas cátedras de ingeniería civil sin obtener un título universitario. ${ }^{28}$ Tras abandonar sus estudios profesionales, Squier se orientó hacia el periodismo. Entre 1841 y 1843 participó como redactor del Literary Pearl en Charlton (Massachusetts) y el New York State Mechanic en Albany (Nueva York). En 1844 fue editor del Whig Daily Journal en Hartford (Connecticut) y en 1845 del Scioto Gazette en Chillicothe (Ohio). ${ }^{29}$

\footnotetext{
${ }^{23}$ Arnold, David. La naturaleza como problema histórico. El medio, la cultura y la expansión de Europa (México: Fondo de Cultura Económica, 2001), p. 148.

${ }^{24}$ Londa Schiebinger, Plants and Empire. Colonial Bioprospecting in the Atlantic World (Cambridge: Harvard University Press, 2004) 174.

${ }^{25}$ Acuña 16.

${ }^{26}$ Lucile Brockway, Science and Colonial Expansion. The Role of the British Royal Botanic Gardens (New Haven: Yale University Press, 2002) 74.

${ }^{27}$ Andrew Lewis, "Gathering for the Republic: Botany in Early Republic America", en Schiebinger, Londa y Swan, Claudia (eds.), Colonial Botany. Science, Commerce, and Politics in the Early Modern World (Philadelphia: University of Pennsylvania Press, 2005) 70.

${ }^{28}$ Terry A Barnhart, Ephraim George Squier and the Development of American Anthropology (Lincoln: University of Nebraska Press, 2009) 21.

${ }^{29}$ Jimmy Avilés, "Ephraim George Squier. Costumbres nicaragüenses", Aguirre, Francisco Xavier (ed.), Cinco semblanzas de Squier (Managua: Fundación Uno, 2005) 162.
} 
La carrera diplomática de Squier inició en 1849, cuando varios intelectuales, incluyendo al historiador William H. Prescott, ${ }^{30}$ recomendaron al joven periodista con el presidente Zachary Taylor para el cargo de chargé d'affaires en Centroamérica. ${ }^{31}$ Los dos principales logros de Squier durante su gestión fueron el Tratado ClaytonBulwer entre los gobiernos de Estados Unidos y Gran Bretaña con el propósito de evitar una confrontación bélica entre ambas naciones en relación con sus disputas por controlar el istmo, ${ }^{32}$ y los tratados con Nicaragua, Honduras y San Salvador, incluido "un acuerdo, nunca ratificado, que permite la construcción de un canal interoceánico ${ }^{33}$ en Estados Unidos a través de Nicaragua". ${ }^{34}$ Ambos logros estuvieron orientados "a promocionar los intereses norteamericanos en la región, anteponiéndolos a las pretensiones hegemónicas que Inglaterra venía ejerciendo en el área". ${ }^{35}$ Squier fue un diplomático que fortaleció el papel estadounidense en el control geopolítico de los recursos naturales centroamericanos.

Además, John M. Clayton, secretario de Asuntos Exteriores de Estados Unidos, encargó a Squier que llevará a cabo una prospección científico-técnica con miras a la construcción de un canal a través de Nicaragua, en especial a partir de sus estudios en ingeniería civil. "Squier puso tal empeño en su misión que apenas a dos meses de su arribo al país había conseguido un contrato, mediante el cual el gobierno de Nicaragua autorizaba a la Atlantic and Pacific Ship-Canal Corporation para abrir una ruta interoceánica a través de su territorio". ${ }^{36}$ La experiencia diplomática de Squier concluyó en julio de 1850 tras la muerte del presidente Taylor. De mediados de 1850 a 1853, Squier residió en Estados Unidos hasta que regresó a Honduras con el propósito de recabar mayores elementos científicos para reactivar el proyecto del ferrocarril que conectara Puerto Cortés (mar Caribe) con el golfo de Fonseca (Océano Pacífico) en Honduras, pues consideró que "sería una manera más factible y económica de transportar bienes y personas a través del istmo centroamericano que un canal interoceánico en Nicaragua". ${ }^{37}$ En 1855, Squier fungió como secretario de The

\footnotetext{
${ }^{30}$ Prescott (1796-1859) fue un prominente intelectual estadounidense interesado en la historia española, mexicana y peruana del siglo XVI.

${ }^{31}$ Francisco Aguirre, "Ephraim George Squier. El embajador erudito", en Aguirre, Francisco Xavier (ed.), Cinco semblanzas de Squier (Managua: Fundación Uno, 2005) 94.

32 Jaime Incer, “Introducción”, en Aguirre, Francisco Xavier (ed.), Cinco semblanzas de Squier (Managua: Fundación Uno, 2005) XIV.

${ }^{33}$ El proyecto del canal nicaragüense no se concretó por la inestabilidad política del país a mediados del siglo XIX, aunado al enfrentamiento entre Estados Unidos y Gran Bretaña por el control de Centroamérica, la inconformidad de los pueblos originarios de la costa caribeña, así como la falta de datos científicos sobre el territorio nicaragüense que propiciaron la falta de capitales que sustentaran la inversión. Véase Acuña, Víctor. "La formación del Estado en Nicaragua y Costa Rica en perspectiva comparada: siglos XIX-XX", Anuario de Estudios Centroamericanos, 44 (2018): 247-285.

${ }^{34}$ Mariana Mould de Pease, "De bibliotecas y experiencias personales: Ephraim George Squier y los orígenes del coleccionismo peruano", en Varón, Rafael y Flores, Javier (dirs.), El hombre y los Andes. Homenaje a Franklin Pease G. Y., t. I (Lima: Instituto Francés de Estudios Andinos, Fondo Editorial de la Pontificia Universidad Católica del Perú, 2002) 126.

${ }^{35}$ Incer XI.

${ }^{36}$ Incer XIII.

${ }^{37}$ Aguirre 102.
} 
Honduras Interoceanic Railway Company, aunque para 1856 la empresa comercial había fracasado. ${ }^{38}$

Squier en 1862 fue designado como comisionado de Estados Unidos en Perú por el presidente Abraham Lincoln. ${ }^{39}$ Su último cargo diplomático fue en 1867 como cónsul de Honduras en New York. ${ }^{40}$ Para Ligia Madrigal, las actividades políticas de Squier representan la ambición estadounidense de "conquistar la ruta del canal con propósitos estratégico-comerciales, que le brindaran la oportunidad de crecer como potencia, lo que estaba sujeta en él a un espíritu de superioridad alimentado por las nociones de la Doctrina Monroe y el Destino Manifiesto". ${ }^{41}$ Squier falleció en 1888 en una institución mental de Brooklyn.

Sus libro más representativos en relación con Centroamérica son: Nicaragua: its People, Scenery, Monuments, and the Proposed Interoceanic Canal (1852), Notes on Central America: particularly the states of Honduras and San Salvador (1855), The states of Central America (1857), Travels in Central America, Particularly in Nicaragua (1860), Tropical fibres: their production and economic extraction (1861), Honduras: Descriptive Historical and Statistical (1870) y Honduras and British Honduras (1880). Los folletos más conocidos son: "Los Volcanes de Centro America y los rasgos geográficos y topográficos de Nicaragua en relación con el proyecto del Canal Interoceánico" (1852) e "Información acerca de las Minas de Carbón del Río Lempa, República de San Salvador, Centro América” (1856). También destaca la entrada "Honduras" de la Encyclopedia Britannica, novena edición (1889), publicada después de su fallecimiento. Sus escritos, proyectos y correspondencia sobre Centroamérica "fueron adquiridos por el historiador Hubert Bancroft, ${ }^{42}$ como las mejores fuentes autorizadas que sirvieron a éste para incorporar Centroamérica a su monumental Historia Universal". ${ }^{43}$ Como se aprecia en la selección bibliográfica, Squier fue uno de los viajeros estadounidenses más versados en los aspectos científicos, económicos y geopolíticos de Centroamérica.

\section{Panorama de Honduras, 1838-1860}

En la historiografía hondureña se considera que el 5 de noviembre de 1838 inició el proceso de construcción del Estado nacional al separarse de la Federación Centroamericana. Desde entonces, los diferentes gobiernos nacionales buscaron delimitar las fronteras internacionales, entablar tratados comerciales con otros países,

\footnotetext{
${ }^{38}$ Liliana Weinberg, "E. G. Squier y la causa del progreso en Nicaragua”, Cuadernos Americanos, 5 (1987) 79.

${ }^{39}$ Mould de Pease 126.

${ }^{40}$ Rafael Heliodoro Valle, "George Ephraim Squier", The Hispanic American Historical Review, V, 4 (1922): 779.

${ }^{41}$ Ligia Madrigal, "Ephraim George Squier. Un enfoque histórico de mentalidades", Aguirre, Francisco Xavier (ed.), Cinco semblanzas de Squier (Managua: Fundación Uno, 2005) 201.

${ }^{42}$ Bancroft (1832-1918) fue un historiador y bibliófilo interesado en el pasado estadounidense, mexicano y centroamericano.

${ }^{43}$ Incer XVII.
} 
atraer colonos europeos e insertar a Honduras en la dinámica económica mundial. ${ }^{44}$ El viaje de E. G. Squier tuvo lugar en el marco de la construcción política del Estado hondureño y el consiguiente ajuste en sus actividades económicas a mediados del siglo XIX. Cabe señalar que la economía nacional se basaba en los intereses de la élite relacionados con la agricultura de consumo interno, la exportación de maderas preciosas, el inicio de la agroexportación de algunas especies comerciales, el comercio nacional, la ganadería y la mediana actividad minera. Hasta 1876, con el inicio de las reformas liberales, la actividad socioeconómica hondureña "se mantuvo inalterada y caracterizada por una distribución dispersa de la población, un mercado nacional limitado y con restringida oportunidad para entrar al mercado mundial" ${ }^{45}$ Las élites hondureñas se beneficiaron del comercio de los cultivos tropicales al destinar la producción al mercado atlántico y ejercer presión política sobre los distintos gobiernos para obtener ventajas hacendarias y en el acaparamiento de predios. ${ }^{46}$

Las maderas preciosas (caoba, cedro y ceiba) fueron el producto de mayor tradición colonial en la exportación, pues se consumían en España y el resto de Europa. Después de 1821, este rubro mantuvo su importancia por la alta demanda comercial. A partir de 1850, la producción cafetalera de Honduras despuntó en la comunidad de Llama, después de la aclimatación de esta especie tras su importación desde Guatemala y El Salvador. ${ }^{47}$ La agroexportación de café estuvo marcada por la demanda de los mercados europeo y estadounidense, así como la concentración de propiedades rurales por parte de grandes hacendados. ${ }^{48}$ En la década de 1860, inició la producción intensiva de bananos hondureños, procedentes de las islas caribeñas con rumbo a Estados Unidos. ${ }^{49} \mathrm{Si}$ bien el comercio bananero es posterior a los periplos de Squier, el diplomático se percató de la capacidad productiva del país.

La ganadería también fue una actividad económica de origen colonial y se mantuvo vigente durante todo el siglo XIX. En la década de 1850 alcanzó importancia como rubro de exportación hacia Cuba por el puerto de Truxillo, el más importante en el golfo de Honduras. ${ }^{50}$ En cuanto a la minería, desde la década de 1820, algunas compañías de Gran Bretaña y Estados Unidos enviaron representantes para explorar la

\footnotetext{
${ }^{44}$ Ismael Zepeda, "Honduras y las relaciones internacionales.1850-1900”, en Revista Estudios, 21 (2008): 51.

${ }^{45}$ Allan Ramos Discua, Claudia Raudales, y Lourdes Fortín, "Las grandes empresas familiares en Honduras: influencia de la intervención del Estado y la inmigración en el siglo XX", Paloma Fernández y Andrea Lluch (eds.), Familias empresarias y grandes empresas familiares en América Latina y España: Una visión de largo plazo (Bilbao: Fundación BBVA, 2015) 320.

${ }_{46}$ Marvin Barahona, Honduras. El estado fragmentado (1839-1876) (México: Centro de Estudios Mexicanos y Centroamericanos, 2015) 38.

${ }^{47}$ Alfonso Carranza, y Jorge Orellana, "La investigación científica en la historia y cultura del café en el Occidente de Honduras (La pequeña propiedad familiar)”, Paradigma, XX, 32 (2013): 144.

${ }^{48}$ Víctor Hugo Acuña, “Crecimiento económico y pobreza: Centroamérica, 1870-1945”, Reflexiones, XXV, 1 (1994) 3.

${ }^{49}$ Vilma Laínez y Víctor Meza, "El Enclave Bananero en la historia de Honduras”, en Anuario de Estudios Centroamericanos, I (1974): 189.

${ }^{50}$ Elizet Payne Iglesias, "El puerto y la región: revisión historiográfica para el estudio del puerto de Truxillo (Honduras)”, Memorias. Revista Digital de Historia y Arqueología desde el Caribe, III, 5 (2006): 13.
} 
viabilidad de obtener concesiones de parte del gobierno, sobre todo en los yacimientos del departamento de Olancho. ${ }^{51}$ Cabe mencionar que las actividades económicas impulsadas por la élite no estuvieron exentas de diversos conflictos locales con las poblaciones nativas, ya fueran de origen indígena, africano o mestizo, debido al avance de las grandes propiedades frente a las de tipo comunal y de auto sustento. ${ }^{52}$

La llegada de viajeros extranjeros, como Squier, fue parte de la dinámica capitalista en la búsqueda global de recursos naturales susceptibles de incorporarlos a la demanda de los países industrializados. ${ }^{53} \mathrm{~A}$ la par, algunos viajeros desarrollaron proyectos para la construcción de un ferrocarril interoceánico en Honduras que competía con las opciones de abrir un canal en México o Nicaragua. Esto muestra cómo Honduras fue presa de "la vorágine de los intereses de Gran Bretaña y Estados Unidos" por apropiarse del istmo en el marco del control geopolítico del comercio interoceánico ${ }^{54}$ En dicho contexto, se suscitó la llamada "Campaña Nacional" contra los filibusteros de William Walker (1855-1857) que ocupaban Nicaragua, guerra en que se aliaron Costa Rica, El Salvador, Honduras y Guatemala. ${ }^{55}$

Durante los distintos viajes de Squier a Honduras (1849 a 1856), los mandatarios de la república en turno negociaron ${ }^{56}$ con Gran Bretaña y Estados Unidos diferentes acuerdos con los cuales mantener un complejo equilibrio en medio de la disputa geopolítica entre las dos potencias por hacerse del control de Centroamérica. En especial, el presidente Juan Nepomuceno Fernández Lindo y Zelaya en 1849 “colocó a la Isla del Tigre bajo un Protectorado de Estados Unidos hasta la suscripción del tratado con Gran Bretaña de 1859, que concluye con la devolución de las Islas de la Bahía y el Territorio de La Mosquitia". ${ }^{57}$ El Tratado Clayton-Bulwer firmado por ambas potencias estableció que colaborarían en la construcción de un canal o ferrocarril en Centroamérica, "sin control absoluto de ninguna de las partes, ni dominio sobre su territorio". ${ }^{58}$

\footnotetext{
${ }^{51}$ Jorge Amaya, Historia de la lectura en Honduras: libros, lectores, bibliotecas, librerías, clase letrada y la nación imaginada en Honduras. 1876-1930 (Tegucigalpa: Universidad Pedagógica Nacional Francisco Morazán, 2009) 41.

${ }^{52}$ Véase Ronald Soto y David Díaz, Mestizaje, indígenas, e identidad nacional en Centroamérica. De la Colonia a las repúblicas liberales (San José: Facultad Latinoamericana de Ciencias Sociales, 2007).

${ }^{53}$ Acuña 2.

${ }^{54}$ Zepeda 56.

55 Véase Carmen Fallas, "La Campaña Nacional 1856-1857. La construcción del Estado nación”, Revista Estudios, 20 (2007): 13-25.

${ }^{56}$ Los gobernantes con los que trató Squier fueron Juan Nepomuceno Fernández Lindo y Zelaya (febrero de 1847 a febrero de 1852), José Trinidad Cabañas (marzo de 1852 a mayo de 1853 y de diciembre de 1853 a octubre de 1855), Francisco de Aguilar (noviembre de 1855 a febrero de 1856) y José Santos Guardiola (febrero de 1856 a febrero de 1860).

${ }^{57}$ Zepeda 51.

58 Josefina Vázquez, "Relaciones interamericanas e intervencionismo", en Miño, Manuel (coord.), La construcción de las naciones latinoamericanas, 1820-1870, t. VI (México: Organización de las Naciones Unidas para la Educación, la Ciencia y la Cultura, Trotta, 2004) 512.
} 
Las élites agropecuarias de Honduras se aliaron con los empresarios estadounidenses al final del siglo XIX en el marco de las reformas liberales, las cuales permitieron la agricultura intensiva de productos tropicales, sobre todo el plátano y el café, cuyo mayor exponente fue la United Fruit Company. ${ }^{59}$ Fue una dinámica económica iniciada en un periodo posterior a esta investigación.

\section{El prólogo y la ciencia}

En el prólogo de Honduras. Descripción Histórica, Geográfica y Estadística de esta República de la América Central, Squier dejó claro los intereses económicos y científicos de su obra, pues se propuso contribuir al proyecto geopolítico de Estados Unidos para construir una comunicación interoceánica en Centroamérica, incluyendo un ferrocarril. Al respecto, el autor indicó que en el año 1849, cuando fungía como representante diplomático de Estados Unidos en Honduras, recorrió el país para recabar información sobre sus recursos naturales y las características del territorio con miras a elaborar una obra científica. Esto se refleja en la mención de Squier sobre sus apreciaciones científicas relativas a la Bahía de Fonseca en el Océano Pacífico. Además, durante su estancia en el puerto salvadoreño de La Unión, el diplomático llevó a cabo estudios meteorológicos para estudiar los "fuertes vientos del norte" y la frecuencia de la lluvia. ${ }^{60}$ Los datos anemométricos indicaron a Squier que existía una interrupción en la cordillera principal de Honduras que la atravesaba de costa a costa, una contradicción en la cartografía de origen colonial que indicaba "una insuperable muralla a los vientos que soplan" del Caribe al Pacífico. ${ }^{61}$ Lo anterior refleja cómo Squier revisó la información científica a su alcance, probablemente reportes en los archivos estadounidenses, pero también en las oficinas del gobierno hondureño. Es notorio que la información científica conocida hasta el momento sobre el territorio de Honduras fue contrastada con la experiencia in situ de Squier, tras lo cual formuló su hipótesis geográfica, base para el proyecto del ferrocarril interoceánico.

Para comprobar la hipótesis de una amplia brecha en la Cordillera Central de Honduras, el diplomático reseñó al público su ascensión al volcán de Conchagua, cerca de La Unión, y cómo en la cima montó un pequeño campamento con el propósito de observar la región. Al respecto, Squier indicó lo siguiente: “fijé mi anteojo hacia el norte, y sin ninguna sorpresa vi que, en efecto, las montañas de Honduras estaban completamente cortadas en aquella dirección". ${ }^{62}$ La práctica científica de Squier, probablemente aprendida durante sus estudios de ingeniería civil, validó su hipótesis acerca de que Honduras representaba la mejor oportunidad para el capital estadounidense de construir un ferrocarril transoceánico con el cual controlar el tráfíco comercial entre Europa, Asia y América.

\footnotetext{
${ }^{59}$ Lainez Vilma y Meza, Víctor 195-198.

${ }^{60}$ Ephraim George Squier. Honduras. Descripción Histórica, Geográfica y Estadística de esta República de la América Central (Tegucigalpa: Tipografía Nacional, 1908) XI.

${ }^{61}$ Ephraim XI.

${ }^{62}$ Ephraim XI.
} 
Squier expresó en el prólogo que su apreciación orográfica fue comprobada en un segundo recorrido entre La Unión y Puerto Cortés llevado a cabo a inicios de 1850. Sin embargo, hasta 1852, Squier sistematizó su experiencia científica en Centroamérica con el propósito de presentar al gobierno estadounidense un proyecto para establecer la comunicación interoceánica en territorio hondureño. Dicha propuesta estuvo en el contexto de las numerosas complicaciones científicas y políticas de los proyectos estadounidenses para construir un canal en el istmo mexicano de Tehuantepec y en Nicaragua. ${ }^{63}$

Con el propósito de recabar la mayor cantidad de datos científicos, Squier encabezó una comisión científico-empresarial con capital estadounidense que llegó a La Unión en abril de 1853, tomando la Bahía de Fonseca por punto de partida y concluyendo en el mar Caribe. La comisión llevó a cabo numerosas observaciones y medidas meteorológicas, geológicas, naturalistas, geográficas y astronómicas para presentar mapas e informes que convencieran a los inversionistas. En la comisión participaron el teniente Jeffers explorando el golfo de Fonseca; el Dr. Woodhouse recorrió el territorio comprendido entre León (Nicaragua) y Comayagua (Honduras); y Squire viajó de Comayagua hasta Santa Rosa de Copán, y de allí a San Salvador (El Salvador), para luego recorrer de Sonsonate a La Unión. ${ }^{64}$ Los comisionados emprendieron varios recorridos entre los tres países con el objetivo de recabar la mayor cantidad de información posible y asegurar que su proyecto contaba con todos los elementos para concretarse. Uno de los resultados de la comisión fue el mapa de Honduras y El Salvador incluido en el libro de Squire, ya que "la convicción de que el interés público no sería satisfecho con un simple detalle de los rasgos físicos" de ambos países, sino con el mapa de mayor precisión científica hasta el momento. Este mapa estuvo al servicio del público estadounidense, incluyendo al gobierno, dejando de lado al pueblo hondureño. La exploración científica abarcó los siete departamentos hondureños: Comayagua, Gracias, Choluteca, Tegucigalpa, Olancho, Yoro y Santa Bárbara. ${ }^{65}$ La comisión indicada es un ejemplo de los proyectos geopolíticos estadounidenses con base en la ciencia para recabar información de primera mano para afianzar su expansión económica. Esto da pie a analizar cómo se construyó la asimetría entre los gobiernos de Honduras y Estados Unidos en la prospección de la naturaleza y el territorio nacionales.

En el mismo sentido, Squier mostró varias complicaciones acaecidas durante la exploración científica, pues "he tenido que seguir mis propias observaciones" debido a la carencia de bibliografía especializada sobre la naturaleza, el territorio y la sociedad de Honduras. ${ }^{66}$ Antes de emprender sus periplos, el viajero acudió a

\footnotetext{
63 Leticia Reina, "Los istmos centroamericanos: Nicaragua, Panamá y Tehuantepec", Dimensión Antropológica, II (1994): 71-94.

${ }^{64}$ Ephraim XIII.

${ }^{65}$ Actualmente Honduras está dividida en diecisiete departamentos: Tegucigalpa, Atlántida, Colón, Comayagua, Copán, Choluteca, Gracias, Intibucá, Islas de la Bahía, Ocotepeque, Olancho, El Paraíso, La Paz, Santa Bárbara, Yoro, Valle y Cortés.

${ }^{66}$ Ephraim XIV.
} 
numerosas librerías, bibliotecas, archivos, instituciones y agrupaciones académicas de Estados Unidos, pero "no hay una sola autoridad acreditada, no hay un solo dato que pudiese servir de núcleo para una agregación de hechos" con el objetivo de iniciar el estudio científico del país". ${ }^{67}$ Squier lamentó que "todo lo que pertenece a la historia", naturaleza, clima, agricultura, población, comercio y "riqueza del país, está en una ignorancia casi completa", incluyendo a las instituciones del gobierno hondureño. ${ }^{68}$ El viajero se presentó ante el público como el experto en todos los rubros relativos a Honduras, es decir, se interesó en erigirse en el especialista sobre el país, con lo cual buscó acaparar la discusión científica en torno al ferrocarril interoceánico para atraer el interés de los gobiernos de Estados Unidos, Gran Bretaña y Honduras, los empresarios y la comunidad científica internacional con el objetivo de ser valorado como una autoridad epistémica. No obstante, el diplomático citó a otros autores de interés: "Thomson, Henderson, Young, Roberts, Dunn, Baily y Brow, que ciertamente contienen hechos y observaciones de mérito". ${ }^{69}$ El señalamiento a libros de viajeros extranjeros, excluyendo a los hondureños o a los letrados del periodo colonial, indica cómo Squier, y muchos otros estadounidenses y europeos, al recorrer Centroamérica eliminó a los intelectuales locales y los individuos que lo auxiliaron en su periplo.

\section{La flora en los departamentos}

La prospección florística efectuada por Squier se plasmó en varias de sus obras y Honduras. Descripción Histórica, Geográfica y Estadística de esta República de la América Central no fue la excepción. Si bien, este viajero también abordó los recursos minerales y faunísticos del país, la flora ocupó varias páginas de más de un capítulo, pues las especies vegetales representaban a mediados del siglo XIX un conjunto de materias primas indispensables para las manufacturas, la agricultura, la industria, la alimentación, el forraje, la terapéutica y el ornato. La flora era el principal recurso natural hondureño, razón por la cual Squier centró su mirada científica en cómo acoplarla a la demanda comercial de su país de origen.

E. G. Squier describió los recursos florísticos de Honduras en el Capítulo VIII relativo a su apreciación sobre cada uno de los departamentos en cuanto a su ubicación geográfica y relación con la economía nacional. Por ejemplo, al abordar al Departamento de Gracias, el viajero indicó que las especies vegetales locales eran comunes a las zonas templadas y tropicales consumidas en las ciudades de Estados Unidos, como trigo, cebada, centeno y papas, las cuales se cultivaban en las montañas por pequeños agricultores, mientras que la caña-miel, índigo, tabaco, café, algodón, cacao, plátano y naranja crecían en los llanos y valles. Otra producción de interés para el mercado estadounidense era la variedad de maderas preciosas, como caoba y brasil, así como pino, "iguales a los mejores de North-Carolina", cedro, granadillo y mora "para objetos de manufacturas y para tintes"; y copal, bálsamo y liquidámbar "entre

\footnotetext{
${ }^{67}$ Ephraim XVI.

${ }^{68}$ Ephraim XVI.

${ }^{69}$ Ephraim XXV.
} 
las gomas, las más comunes". ${ }^{70}$ La descripción de los productos vegetales se orientó a complementar el mercado económico de su país de origen. La práctica naturalista de Squier fue mediada por el aspecto comercial y colonizante y no por la prospección taxonómica interesada en la determinación de nuevas especies.

Otra mención se refiere al Departamento de Yoro, en que los ríos de los valles albergaban maderas preciosas y "puede describirse el departamento como el distrito de caoba en Centro América". ${ }^{71}$ Los habitantes, en general, eran cortadores de madera por lo que no era necesario importar trabajadores desde Estados Unidos, tan solo hacía falta fundar empresas comerciales que vendieran la caoba a gran escala en varias partes del mundo, así como contratar ingenieros que dirigieran a los trabajadores hondureños. ${ }^{72}$ El proyecto colonizador en Honduras fue claro al abordar el corte de caoba para surtir al mercado estadounidense y europeo. Esto ayudaría a que las empresas estadounidenses controlaran varios de los recursos vegetales hondureños a través de un posible convenio gubernamental que incluyera la migración de cuadros técnicos para implementar prácticas modernas con las cuales intensificar el desmonte del departamento en cuestión. El libro de Squier no muestra si entabló una relación directa con los trabajadores, pero sí observó cómo incorporarlos a las empresas estadounidenses que en el futuro se asentarían en Honduras.

En cuanto al Departamento de Santa Bárbara, Squier señaló que en su recorrido por los ríos Ulúa, Blanco, Santiago, Santa Bárbara y Chamelecón había observado que los valles aledaños presentaban gran fertilidad para la agricultura y "están todos cubierto de altos bosques, con unos pocos pedazos de tierra cultivados en las inmediaciones de los pueblos que están diseminados a lo largo del Camino Real". ${ }^{33}$ La mayor riqueza de los bosques era copal, hule, palo de rosa, sangre de dragón y sobre todo caoba, la cual empezaba a extraerse con rumbo a Nueva Orléans a través de barcas que surcaban los ríos Ulúa y Chamelecón hacia el mar Caribe. Squier llamó la atención al lector acerca de este departamento, el cual a su juicio era el más feraz, "no solo por sus ricos productos naturales sino por su inmediación a los puertos, por sus ríos navegables y por su facilidad para cultivarlo, propio para el algodón, vainilla, zarzaparrilla, café y toda clase de frutos tropicales", así como la producción de cacao, llamado cacao mico, superior a las variedades de Nicaragua y Soconusco. Dicha variedad era "indígena y los habitantes lo recogen de árboles silvestres en los bosques". ${ }^{74} \mathrm{El}$ autor centró su mirada en tres rubros: maderas preciosas, productos alimenticios (bebidas, condimentos y alimentos) y materias primas para la industria. A partir de éstos, Squier efectuó su estudio geopolítico sobre la naturaleza de Honduras. El reconocimiento de las especies útiles a la economía se acompañó de una evaluación de la cantidad y capacidad de la mano de obra local, como un elemento de la estrategia geopolítica del colonialismo estadounidense.

\footnotetext{
${ }^{70}$ Ephraim 131.

${ }^{71}$ Ephraim 133.

${ }^{72}$ Ephraim 133.

${ }^{73}$ Ephraim 151.

${ }^{74}$ Ephraim 151.
} 


\section{Las producciones vegetales indígenas}

El capítulo XI "Producciones vegetales" abordó dos tipos de especies con aprovechamiento económico: indígenas y aclimatadas. Las primeras eran tanto las conocidas en el mercado estadounidense y europeo como las desconocidas fuera de Honduras. El libro prospectivo de Squier describió varias plantas que suscitarían el interés de los empresarios de su país. Al inicio del capítulo, el diplomático señaló que las maderas preciosas "son las que forman el principal ítem de las exportaciones del Estado", en especial la caoba. ${ }^{75}$ La Swietenia mahogoni, llamaba la atención "por su grande y magnífico follaje", así como por la altura y grosor del tronco. Squier describió la caoba como un árbol que

crece con gran lentitud, haciendo un aumento apenas perceptible en los estrechos límites de la vida de un hombre. Se ha calculado que hasta los trescientos años está para cortarse. Se podrá formar una idea de la enormidad a que llega algunas veces, sabiendo que en la parte más baja de un árbol, un tronco de 17 pies de largo, ha tenido cinco pies, seis pulgadas cuadradas, iigual a 550 pies cúbicos y a un peso de 17 toneladas! La caoba crece casi en todas partes de Honduras, especialmente en los valles de varios ríos. Sin embargo, donde es más abundante, es en los bajos inmediatos a los ríos que corren a la Bahía de Honduras, donde llega a su mayor lozanía, y en donde están los principales trabajos, que los españoles llaman cortes. Como la mayor parte de los terrenos son propiedad del Estado, las maderas se cortan con licencia del gobierno, mediante una suma fija por cada árbol. Excepto los trabajos que están en las bocas de algunos ríos para recibir, marcar y embarcar las maderas que vienen por ellos, los demás establecimientos son temporales, cambiándose de tiempo en tiempo, según van escaseando los árboles de las inmediaciones. ${ }^{76}$

Esta descripción es de las pocas que Squier dedicó a una especie vegetal, dada la importancia económica que representaba en la economía mundial y en Honduras. El viajero mostró su amplio conocimiento in situ sobre el país, es decir, mostró al público que la información recabada era de primera mano y novedosa, a partir de su experiencia y no solo como un mero compilador de datos de otros autores. Squier visitó las localidades más relevantes para señalar dónde sería factible establecer empresas coloniales que surtieran de materia prima a las fábricas en el marco del proyecto geopolítico estadounidense.

Como en el "Prólogo", Squier reiteró sobre el comercio de maderas provenientes de Honduras, "como de todos los otros ramos de industrias, no tenemos ningún dato de sus productos", por lo que carecía de información concreta de la producción anual, aunque consideraba que era cuantiosa por sus visitas a las zonas madereras en los ríos Ulúa, Aguán, Negro y Patuca, y a las casas exportadoras. ${ }^{77}$ Otras maderas hondureñas poco conocidas eran la llamada de rosa (Amiris balsamiferah) de la costa norte, "donde ha comenzado a ser un artículo de comercio", y el guanacaste

\footnotetext{
${ }^{75}$ Ephraim 189.

${ }^{76}$ Ephraim 191.

${ }^{77}$ Ephraim 203.
} 
(Ramnus sarcomphalus), abundante en el valle de Ulúa y en las márgenes de los ríos del valle de Comayagua. ${ }^{78}$ Entre las especies tintoreas destacaban el fustoc o palo amarillo (Morus tinctoria), sándalo amarillo (Santalum album), brasil (Casalpina echinata), sangre de dragón (Peterocarpus draco) y achiote (Bixa orellana).$^{79}$ El libro mostró las especies susceptibles de explotar de forma intensiva, aprovechando la mano de obra local, pero con capital estadounidense y así posicionar las nuevas maderas preciosas en el mercado atlántico para reforzar el crecimiento económico de su patria.

En cuanto a las especies productoras de gomas y medicinas, el viajero determinó que la principal era la goma arábiga (Acacia arabiga) ubicada en los declives montañosos del Pacífico. Además, en los bosques occidentales habitaba la copaiba (Copaifera officinalis), el liquidámbar (Styrax officinalis), el copal (Hedwigia balsaminifera), la palma cristi (Ricinus communis), la ipecacuana (Carapichea ipecacuanha) y el caoutchouc (Siphonia elastica). ${ }^{80}$ El señalamiento de otras especies hondureñas ya sancionadas por su utilidad comercial en otros países fue una estrategia para ampliar el interés del público en la obra de Squier, en el sentido de mostrar cómo su prospección abría diferentes oportunidades económicas. El autor no refirió cómo influiría su obra en el desarrollo económico de Honduras, dejando al margen los intereses locales. Una postura geopolítica común en el colonialismo estadounidense de mediados del siglo XIX.

Después de la caoba, el cedro (Cedrola odorata) ocupaba el segundo lugar entre las maderas de uso común entre la sociedad hondureña, gracias a que se encontraba a disposición de los habitantes de todos los valles y en los principales ríos inmediatos a la costa. Entre las características físicas que lo hacían tan popular, Squier resaltó que no lo atacaban los insectos, la madera era fácil de trabajar, presentaba un agradable olor y llamativo color para objetos de uso común, “por esta razón es más usado en Honduras que ninguna otra madera". ${ }^{81}$ Squier recomendó exportar cedro a Estados Unidos para vender la madera entre los artesanos, pues resultaría una importación barata desde Honduras por el bajo sueldo de la mano de obra local. Cada especie de importancia comercial fue analizada por Squier, incluyendo recomendaciones para incorporarla a la economía estadounidense.

A Squier le atrajo la ceiba (Bombax ceiba) y su peculiar aprovechamiento por parte de los artesanos hondureños para confeccionar prendas de vestir. Lo más llamativo fue que este árbol florecía entre dos y tres veces al año, cuando aportaba "una hermosura particular a todo el bosque" y la vaina del fruto albergaba un suave y fino algodón que "podría servir para otros objetos de más utilidad". ${ }^{82}$ Si bien Squier no hizo un comentario acerca de la exportación del algodón de la ceiba, sí le pareció destacable como una curiosidad vegetal, digna de estudio por los naturalistas de Estados Unidos.

\footnotetext{
${ }^{78}$ Ephraim 203.

${ }^{79}$ Ephraim 204.

${ }^{80}$ Ephraim 204.

${ }^{81}$ Ephraim 205.

${ }^{82}$ Ephraim 206.
} 
Squier también mencionó las principales especias de Honduras. En primer lugar, el pimiento indio semejante al de la isla de Jamaica (Myrtus pimenta), cuyas bayas eran más grandes que la especie jamaiquina, presentaban un aroma más suave "y no tiene gran consumo en el comercio del país". ${ }^{83}$ La zarzaparrilla centroamericana (Smilax medicinal) era reconocida como de gran calidad y se producía al norte de las costas orientales por los "indios, pero nunca en una cantidad que pueda servir para cambiar artículos manufacturados de Europa, como fundadamente se debe esperar que suceda". ${ }^{84}$ Por último, la vainilla (Epidendrum vanilla) crecía en los mismos lugares que la zarzaparrilla, siendo notable el mayor tamaño de las vainas frente a la variedad mexicana, las cuales no habían sido "un artículo de comercio, pero los ensayos que se han hecho en Estados Unidos y en Europa, han producido órdenes aún más de la que suministran las costas". ${ }^{85}$ La tres especies reconocidas por el viajero ya formaban parte del comercio mundial de especias, pero no se exportaban desde Honduras. Por esta razón, Squier recomendó fundar casas comerciales que cultivaran y cosecharan estos recursos vegetales poco aprovechados por el pueblo hondureño. Resalta la mención de Squier sobre los ensayos estadounidenses de la vainilla hondureña, lo que muestra la importancia de la sanción científica de las especies vegetales para iniciar su comercio internacional.

El último producto indígena de interés para Squier fue la caña-miel, especie centroamericana y diferente a la asiática, por ser más blanda y delgada, la cual contenía proporcionalmente más jugo azucarado. De acuerdo con la observación de Squier, ésta crecía en elevaciones de tres a cuatro mil pies. Anualmente daba dos cortes, y en circunstancias favorables, hasta tres, y requería una nueva plantación hasta pasados diez años. El azúcar de la caña-miel era fina, y, "con algún cuidado al fabricarla, sale tan blanca y tan refinada como la del comercio. No hay grandes establecimientos de fabricación, pero por todo el Estado se encuentran pequeños molinos movidos por bueyes, que producen la necesaria para el consumo del pueblo" ${ }^{86}$ La mayor parte se producía en forma de chancaca o azúcar baja, en pequeños panes de una o dos libras, que transportaban envueltos en hojas de plátano. ${ }^{87}$ Squier detectó una oportunidad de convertir el consumo local de la caña-miel en uno de envergadura mundial, una vez que se comprobara que esta especie hondureña lograría competir contra la caña de azúcar, tan apreciada por los consumidores del mundo. El autor no profundizó en el tema, pero se aprecia cómo detectó oportunidades comerciales mediante el uso cotidiano de la flora local por la sociedad hondureña. Esta detección fue posible al recorrer el país en varias ocasiones, tomar nota de la flora y su utilidad local y relacionar la expansión económica estadounidense con las materias primas de Honduras.

\footnotetext{
${ }^{83}$ Ephraim 207.

${ }^{84}$ Ephraim 208.

${ }^{85}$ Ephraim 208.

${ }^{86}$ Ephraim 209.

${ }^{87}$ Ephraim 209.
} 


\section{Producciones vegetales aclimatadas}

La segunda parte del Capítulo IX presentó las especies de plantas aclimatadas en Honduras, las cuales habían sido promovidas por diferentes gobiernos para que el país compitiera en el mercado agroexportador mundial, siguiendo la exitosa vía de Costa Rica al producir café. Al respecto, Squier mencionó que la variedad hondureña de la Coffea arabica presentaba "excelente calidad", aunque aún no representaba un artículo relevante de producción comercial ni su cultivo era suficiente para saciar el consumo nacional. Y añadió: "He visto varios plantíos abandonados, en el Departamento de Gracias, cuyos arbustos eran agobiados con el peso de las bayas". ${ }^{88}$ El diplomático mencionó cómo la cosecha de Costa Rica en 1851 produjo 20,000,000 de libras, teniendo en el mercado inglés un precio medio de 12.5 pesos por quintal, igual a 2,500,000 pesos. Al respecto, Squier indicó: "Hay muchas razones para creer que el café de Honduras será tan bueno como el de Costa Rica" ${ }^{89}$ La mención sobre la exportación de café indica que Squier detectó un rubro comercial potencialmente rentable para el capital estadounidense y que compitiera con las variedades de otros países centroamericanos y sudamericanos. A la larga, la aclimatación de plantas extranjeras produjo un cambio en el paisaje hondureño. ${ }^{90}$ El hecho de que Squier hiciera comparaciones entre ambos países muestra la mirada geopolítica del diplomático sobre los recursos naturales del subcontinente.

En cuanto al tabaco, el viajero advirtió que este producto vegetal se había posicionado con "gran celebridad en todo Centro-América", en particular el proveniente de los llanos de Santa Rosa "se considera como el primero del mundo". 91 Gracias al tabaco, el pueblo de Santa Rosa se había transformado en una próspera ciudad, la más importante del departamento y rivalizaba con la antigua ciudad de Gracias. ${ }^{92}$ A diferencia del café, el tabaco fue una planta de gran dinamismo económico por su exportación hacia Estados Unidos. Squier, como en otros pasajes, reconoció la existencia de mano de obra barata y calificada, la cual requería de una nueva directriz científico-técnica para modernizar su aprovechamiento e intensificar el comercio mundial.

El índigo fue la última especie aclimatada expuesta por el autor, la cual se cultivaba a pequeña escala a partir de su importación desde Guatemala hacia los distritos de Camasca y Guarita, en el departamento de Gracias; y los de Aramesina, Caridad y San Antonio del Norte, en el departamento de Comayagua. Para Squier, el índigo hondureño competía en calidad con la producción de Guatemala, Nicaragua y El Salvador, y envió una muestra a un farmacéutico de Boston, sin indicar el nombre, para que efectuara un análisis químico que confirmara su superioridad frente a las variedades de la India y Guatemala. El autor consideró que el índigo podría extenderse

\footnotetext{
${ }^{88}$ Ephraim 210.

${ }^{89}$ Ephraim 210.

${ }^{90}$ Véase Augusto Cazali, "El desarrollo del cultivo del café y su influencia en el régimen del trabajo agrícola. Época de la Reforma liberal (1871-1885)”, Anuario de Estudios Centroamericanos, II (1976): 35-93.

${ }^{91}$ Ephraim 211.

${ }^{92}$ Ephraim 211.
} 
"con facilidad y ventajas en todo el valle de Chamelecón y en los de otros ríos que caen a la Bahía de Honduras". ${ }^{93}$ El señalamiento sobre la sanción química indica una de las estrategias de la prospección naturalista de Squier al reconocer y explicar los recursos vegetales de Honduras para luego comprobar su calidad y cómo se insertarían en el mercado mundial, en este caso a través de la sanción química efectuada en Estados Unidos y excluyendo a Honduras de este proceso científico. También resalta que Squier advirtió que los recursos naturales de Honduras estaban compartidos con el resto de Centroamérica, por lo que la competencia económica estaba creciendo. Lo anterior representaba una oportunidad para el capital estadounidense al incursionar en la venta del índigo hondureño. La prospección florística de Squier estuvo permeada por las estrategias geopolíticas de su gobierno para incorporar las especies centroamericanas, en particular las de Honduras, a la dinámica económica, ya fuera para la industria, el comercio o la agricultura.

\section{Conclusiones}

La literatura de viaje es una fuente destacada en la historia de la ciencia latinoamericana por el tipo de información que plasmó cada autor y sus propósitos para ello. En numerosos casos, se trató de viajeros europeos y estadounidenses que recorrieron América Latina con el propósito de reconocer las oportunidades económicas que presentaban los jóvenes países, sobre todo en la búsqueda de materias primas desde su estudio científico.

Ephraim George Squier recorrió varios países latinoamericanos entre 1849 y 1864, ya fuera como diplomático o empresario. Honduras fue uno de los países que más llamaron la atención de Squier, pues le dedicó tres libros y una entrada de la Encyclopedia Britannica. Otros países a los que también dedicó más de una obra fueron Nicaragua y El Salvador. La mirada viajera de Squier estuvo orientada por el proyecto geopolítico de Estados Unidos en cuanto a la apropiación de los recursos naturales de Centroamérica a partir de la prospección científica de la flora de cada país. La expansión económica estadounidense de mediados de la centuria tuvo lugar en el marco de la rivalidad con Gran Bretaña por controlar el istmo americano.

La edición de Honduras. Descripción Histórica, Geográfica y Estadística de esta República de la América Central muestra cómo Squier en sus recorridos por el país estuvo atento a la flora con utilidad para la economía estadounidense, ya fuera con productos de consumo (tabaco, café, vainilla, etcétera) o materias primas para las actividades artesanales e industriales (caoba, hule, cedro, etcétera). En escasas ocasiones el autor dedicó atención a especies poco conocidas en el mundo por el mero interés botánico, es decir, en sus aspectos organográficos, fisiológicos y taxonómicos. Squier fue un botánico estadounidese que desarrolló una práctica científica amateur sesgada por el interés económico y la geopolítica de su país de origen.

${ }^{93}$ Ephraim 212. 
El libro del diplomático estadounidense presentó un panorama de la naturaleza hondureña en cuanto a la diversidad de los departamentos del país y después en relación con el tipo de flora útil: nativa y aclimatada. Resalta que Squier observó que varias plantas formaban parte de la economía nacional, algunas desde tiempos coloniales, pero carecían de la modernización científico-técnica para aumentar y mejorar su aprovechamiento. Esto último recomendaba que se encaminara mediante empresas estadounidenses a manera de una colonización informal del país. También se aprecia que Squier valoró los rubros productivos de Honduras para recomendar cómo acoplarlos a la expansión económica de Estados Unidos, sin tomar en cuenta los proyectos de la élite nacional o de los grupos de trabajadores. En el libro de viaje no es claro que Squier mantuviera una estrecha interacción con hacendados, ganaderos o comerciantes locales.

La agroexportación fue el modelo productivo que empezó a desarrollarse en Honduras a mediados del siglo XIX. Para ello fue importante la prospección que varios viajeros hicieron sobre el país para dar a conocer los recursos naturales y cómo vincularlos con las economías de Estados Unidos y Europa occidental. La bibliografía producida Squier y otros autores se dirigió a los grupos económicos y políticos de los países de origen de cada uno de los autores para despertar el interés por aprovechar los recursos naturales como el caso de Honduras. Se trata de viajeros que practicaron la ciencia a partir de la política de colonialismo sin colonias, dejando de lado a la población local.

La prospección de la flora nativa realizada por Squier estuvo presente de forma continua a lo largo de su libro con el objetivo de mostrar al lector los recursos naturales hondureños. En varios casos, como la caoba, la ceiba o la caña-miel, el viajero incluso describió el tipo de mano de obra vinculada y su incipiente exportación con miras a indicar las posibilidades de que las empresas estadounidenses se establecieran en las mismas localidades para intensificar la explotación de las plantas productivas. Por ello, Squier insistió en las oportunidades económicas de las especies vegetales de dicho país desde su papel como diplomático y científico amateur.

La flora aclimatada fue el segundo grupo de especies de interés de Squier, pues ya formaban parte del mercado mundial, como el tabaco, el café o la vainilla. En este caso, el viajero presentó las oportunidades de utilizar las características territoriales de Honduras para su producción o intensificar el pequeño aprovechamiento que ya se efectuaba para el mercado local a partir del control de las empresas estadounidenses antes de que lo hicieran las británicas. La botánica fue la ciencia que hizo posible que Squier llevara a cabo la prospección de la flora hondureña a partir de los intereses económicos del país que representaba con su cargo diplomático.

La revisión histórica de otras obras de Squier sobre Honduras permitirá reconocer la impronta científica del autor en sus relatos de viaje y si mantuvo un interés constante en la flora latinoamericana. También queda pendiente para futuras investigaciones el análisis de la literatura producida por otros viajeros que recorrieron Honduras y Centroamérica en el siglo XIX para efectuar otras prospecciones científicas de la naturaleza. 


\section{Bibliografía}

\section{Fuentes primarias}

Squier, Ephraim George. Honduras. Descripción Histórica, Geográfica y Estadística de esta República de la América Central. Tegucigalpa: Tipografía Nacional, 1908.

\section{Fuentes secundarias}

\section{Libro}

Amaya, Jorge. Historia de la lectura en Honduras: libros, lectores, bibliotecas, librerías, clase letrada y la nación imaginada en Honduras. 1876-1930. Tegucigalpa: Universidad Pedagógica Nacional Francisco Morazán, 2009.

Arnold, David. La naturaleza como problema histórico. El medio, la cultura y la expansión de Europa. México: Fondo de Cultura Económica, 2001.

Barahona, Marvin. Honduras. El estado fragmentado (1839-1876). México: Centro de Estudios Mexicanos y Centroamericanos, 2015.

Barnhart, Terry A. Ephraim George Squier and the Development of American Anthropology. Lincoln: University of Nebraska Press, 2009.

Brockway, Lucile. Science and Colonial Expansion. The Role of the British Royal Botanic Gardens. New Haven: Yale University Press, 2002.

Nieto-Galan, Agustí. Los públicos de la ciencia. Expertos y profanos a través de la historia. Madrid: Marcial Pons Historia, 2011.

Ortas, Esther. Viajeros ante el paisaje aragonés (1759-1850). Zaragoza: Consejo Superior de Investigaciones Científicas, 1999.

Osterhammel, Jürgen y Jan Jansen. Colonialismo. Historia, formas, efectos. Madrid: Siglo XXI, 2019.

Pratt, Mary Louise. Imperial Eyes. Travel Writing and Transculturation. New York: Routledge Taylor and Francis Group, 2003.

Schiebinger, Londa. Plants and Empire. Colonial Bioprospecting in the Atlantic World. Cambridge: Harvard University Press, 2004.

Soto, Ronald y Díaz, David. Mestizaje, indígenas, e identidad nacional en Centroamérica. De la Colonia a las repúblicas liberales. San José: Facultad Latinoamericana de Ciencias Sociales, 2007. 


\section{Capítulos de libros}

Aguirre, Francisco. "Ephraim George Squier. El embajador erudito", en Aguirre, Francisco Xavier (ed.), Cinco semblanzas de Squier. Managua: Fundación Uno, 2005.

Albuquerque, Luis. "Los libros de viaje como género literario", en Lucena, Manuel y Pimentel, Juan (eds.), Estudios sobre literatura de viajes. Madrid: CSIC, 2006.

Avilés, Jimmy. "Ephraim George Squier. Costumbres nicaragüenses", en Aguirre, Francisco Xavier (ed.), Cinco semblanzas de Squier. Managua: Fundación Uno, 2005.

Azuela, Luz Fernanda. "Imperialismo y ciencia. La Royal Geographical Society en el Perú (1880-1900)", en Escandón, Patricia y Azuela, Luz Fernanda (coords.), Historia del quehacer científico en América Latina. México: Universidad Nacional Autónoma de México, 1993.

Brannstrom, Christian y Gallini, Stefania. "An Introduction to Latin American Environmental History”, en Brannstrom, Christian (ed.), Territories, Commodities and Knowledges. Latin American Environmental Histories in the Nineteenth and Twentieth Centuries. London: Institute for the Study of the Americas, 2004.

Discua, Allan, Ramos, Concepción, Raudales, Claudia y Fortín, Lourdes. "Las grandes empresas familiares en Honduras: influencia de la intervención del Estado y la inmigración en el siglo XX”, en Fernández, Paloma y Lluch, Andrea (eds.), Familias empresarias y grandes empresas familiares en América Latina y España: Una visión de largo plazo. Bilbao: Fundación BBVA, 2015.

Incer, Jaime. “Introducción”, en Aguirre, Francisco Xavier (ed.), Cinco semblanzas de Squier. Managua: Fundación Uno, 2005.

Lewis, Andrew. "Gathering for the Republic: Botany in Early Republic America”, en Schiebinger, Londa y Swan, Claudia (eds.), Colonial Botany. Science, Commerce, and Politics in the Early Modern World. Philadelphia: University of Pennsylvania Press, 2005.

Madrigal, Ligia. "Ephraim George Squier. Un enfoque histórico de mentalidades", en Aguirre, Francisco Xavier (ed.), Cinco semblanzas de Squier. Managua: Fundación Uno, 2005.

Mould de Pease, Mariana. "De bibliotecas y experiencias personales: Ephraim George Squier y los orígenes del coleccionismo peruano", en Varón, Rafael y Flores, Javier (dirs.), El hombre y los Andes. Homenaje a Franklin Pease G. Y., t. I. Lima: Instituto Francés de Estudios Andinos, Fondo Editorial de la Pontificia Universidad Católica del Perú, 2002. 
Vázquez, Josefina. "Relaciones interamericanas e intervencionismo", en Miño, Manuel (coord.), La construcción de las naciones latinoamericanas, 1820-1870, t. VI. México: Organización de las Naciones Unidas para la Educación, la Ciencia y la Cultura, Trotta, 2004.

\section{Tesis, ponencias y otros}

Chozas, Diego. La literatura de viaje en El Museo Universal (1857-1869), (tesis de doctorado), Universidad de Zaragoza, 2014.

\section{Artículos de revistas}

Acuña, Víctor Hugo. "Centroamérica en las globalizaciones (siglos XVI-XXI)", en Anuario de Estudios Centroamericanos, XLI (2015).

Acuña, Víctor Hugo. “Crecimiento económico y pobreza: Centroamérica, 18701945”, en Reflexiones, XXV, 1 (1994).

Acuña, Víctor. "La formación del Estado en Nicaragua y Costa Rica en perspectiva comparada: siglos XIX-XX", en Anuario de Estudios Centroamericanos, 44 (2018).

Bernecker, Walther L. "Literatura de viajes como fuente histórica para el México decimonónico: Humboldt, inversiones e intervenciones”, en Tzintzun, 38 (2003).

Carranza, Alfonso y Orellana, Jorge. "La investigación científica en la historia y cultura del café en el Occidente de Honduras (La pequeña propiedad familiar)", en Paradigma, XX, 32 (2013).

Cazali, Augusto. "El desarrollo del cultivo del café y su influencia en el régimen del trabajo agrícola. Época de la Reforma liberal (1871-1885)", en Anuario de Estudios Centroamericanos, II (1976).

Fallas, Carmen. "La Campaña Nacional 1856-1857. La construcción del Estado nación”, en Revista Estudios, 20 (2007).

Gallini, Stefanía. "Historia, ambiente, política: el camino de la historia ambiental en América Latina", en Nómadas, 30 (2009).

Laínez, Vilma y Meza, Víctor. "El Enclave Bananero en la historia de Honduras”, en Anuario de Estudios Centroamericanos, I (1974).

Parra, Alma, "Cónsules y empresarios, expresión local del expansionismo estadounidense hacia finales del siglo XIX”, en Secuencia, 48 (2000).

Payne Iglesias, Elizet, "El puerto y la región: revisión historiográfica para el estudio del puerto de Truxillo (Honduras)", en Memorias. Revista Digital de Historia y Arqueología desde el Caribe, III, 5 (2006). 
Reichert, Rafal. "El golfo de Honduras: estrategias geopolíticas y militares de una frontera imperial, siglos XVI-XVIII", en Tzintzun, 65 (2017).

Reina, Leticia. "Los istmos centroamericanos: Nicaragua, Panamá y Tehuantepec”, en Dimensión Antropológica, II (1994).

Rodríguez Gómez, Juan. “La literatura de viajes como fuente histórica: aproximación a las observaciones políticas de los viajeros colombianos en Venezuela", en Historia Crítica, 16 (1999).

Romero, Leonardo. "Imágenes poéticas en textos de viajes románticos al sur de España”, en Revista de Literatura, LXXIII, 145 (2011).

Rubio, María. "En los límites del libro de viajes: seducción, canonicidad y transgresión de un género", en Revista de Literatura, LXXIII, 145 (2011).

Uzcanga, Francisco. "El relato de viaje en la prensa de la Ilustración: entre el prodesse et delectare y la instrumentalización satírica", en Revista de Literatura, LXXIII, 145 (2011).

Vacher, Jean-Joinville y López Beltrán, Clara. "Prólogo", en Bulletin de L'Institut Français d'Études Andines, vol. XXXII, 3 (2003).

Valle, Rafael Heliodoro. "George Ephraim Squier", en The Hispanic American Historical Review, V, 4 (1922).

Weinberg, Liliana. "E. G. Squier y la causa del progreso en Nicaragua", en Cuadernos Americanos, 5 (1987).

Zepeda, Ismael. "Honduras y las relaciones internacionales.1850-1900”, en Revista Estudios, 21 (2008). 